\title{
A Comparison of an Integrated Three-dimensional Biomechanical Analysis of High-speed Incline and Level Treadmill running in Elite Football Players
}

\author{
${ }^{1}$ Amrinder Singh, ${ }^{2}$ Deepchand Nigam Arvind, ${ }^{3}$ Jaspal Singh Sandhu
}

\begin{abstract}
Purpose: Recent sprint training regimens have used high-speed incline treadmill running to provide enhanced loading of muscles responsible for increasing forward running speed. The purpose of this study was to determine the standard alterations in the lower-limb joint kinematics and gait parameters resulting from changes in treadmill slope during the use of the treadmill as a medical reference.
\end{abstract}

Subjects: The subjects of this study were 20 normal, healthy elite football players without any orthopedic, respiratory, or cardiovascular system problems.

Materials and methods: The running gait of subjects was analyzed using motion analysis system on an inclined treadmill with three running trials, each for 3 minutes. The gait was measured at incline of 0,9 , and $18 \%$. The speed of the treadmill was fixed at $4.0 \mathrm{~m} / \mathrm{s}$ in order to maintain a constant running speed.

Results: The subjects' gait parameters were observed to change significantly between slopes of 0 and $18 \%$. The results showed greater maximum knee flexion, ankle dorsiflexion, and total hip range of motion (ROM) in incline treadmill running compared to level running.

Conclusion: The results of this study can be put in as a predesigned rehabilitation program for sprint training on a treadmill, especially for treadmills with adjustable gradients.

Keywords: Inclined treadmill, Kinematics, Running gait.

How to cite this article: Singh A, Arvind DN, Sandhu JS. A Comparison of an Integrated Three-dimensional Biomechanical Analysis of High-speed Incline and Level Treadmill running in Elite Football Players. J Postgrad Med Edu Res 2016;50(4):185-189.

Source of support: The set-up was organized by the Department of Sports Medicine and Physiotherapy, Guru Nanak Dev University, Amritsar, Punjab, India and there was no funding issues.

Conflict of interest: None

\section{INTRODUCTION}

Running is another locomotor activity, i.e., similar to walking, but certain differences need to be examined.

\footnotetext{
${ }^{1}$ Assiatant Professor, ${ }^{2}$ Research Scholar, ${ }^{3}$ Professor

${ }^{1-3}$ Department of Sports Medicine and Physiotherapy, Guru Nanak Dev University, Amritsar, Punjab, India

Corresponding Author: Amrinder Singh, Department of Sports Medicine and Physiotherapy, Guru Nanak Dev University Amritsar, Punjab, India, Phone: +919501114474 , e-mail: singhamrinder_30@yahoo.com
}

Running requires greater balance, muscle strength, and range of motion (ROM) than does normal walking. ${ }^{1}$ Greater balance is required because running is characterized not only by a considerably reduced base of support but also by an absence of the double-support periods observed in normal walking and the presence of float periods in which both feet are out of contact with the supporting surface. ${ }^{1}$ For running and cutting sports, short burst acceleration is one of the major discriminators between elite and sub-elite athletes. ${ }^{2,3}$ Efficient and effective training methods to improve speed are often sought after by coaches and athletes in order to enhance this important performance characteristic. While most athletes' desire improved acceleration and speed, the most effective training mode to obtain improvements in these measures is unclear. ${ }^{4}$

The integration of kinematic, kinetic, and electromyogram (EMG) data has provided a wealth of information on the coordination of the musculoskeletal system during level running. ${ }^{5}$ In contrast, fewer studies have focused on the biomechanics of incline running, although substantial changes in lower extremity motion have been reported with alterations in grade of $5 \%$ or more. ${ }^{6}$ Studies on the kinetics of graded running have been limited to the stance phase only. ${ }^{7}$ Although the effect of grade on lower extremity muscle activity has been well documented for walking, similar studies on graded running are absent. ${ }^{8}$

Recent training regimens intended to improve sprinting performance have included incline treadmill running at speeds above $4.5 \mathrm{~m} / \mathrm{s}$ with grades over $30 \%{ }^{9}$ These training protocols are designed to enhance muscular loading of the hip, knee, and ankle extensors during stance and the hip flexors and extensors during recovery. ${ }^{9}$ It has been suggested that these muscle groups are primarily responsible for generating forward propulsion during running and sprinting. ${ }^{10}$

Running involves a bouncy gait in which energy is absorbed passively by muscles and tendons in a leg whenever a foot hits the ground, so that the body can be momentarily slowed and lowered. ${ }^{1,11}$ Much of that absorbed energy is then used to lift and accelerate the body during the latter part of foot-strike, so that toe-off can be accomplished and an athlete can "fly" through the 
air toward an eventual collision of the other foot with the ground. Scientific research has proven that setting the treadmill to a $1 \%$ grade accurately reflects the energy costs and simulates outdoor running. ${ }^{1,11}$

Both ground-based and treadmill-based speed training techniques provide mechanical load, which has the potential to initiate adaptations to stride frequency, stride length, and ultimately, acceleration and sprinting speed. ${ }^{12}$ In general terms, running speed is the product of stride length and stride frequency. Attempts to improve speed must induce neuromuscular adaptations that increase either stride length or stride frequency without significant detriment to the other. ${ }^{12}$

Speed training on a treadmill provides load resistance based on spatial position and gravitational pull during bouts performed on inclines with greater than $0 \%$ grade. ${ }^{12}$ Inclined treadmill sprinting creates adaptations in stride frequency by increasing lower extremity muscle activation and through increases in joint angular velocities. ${ }^{13}$ In contrast, ground-based speed training techniques provide load via horizontal resistance (i.e., weighted sled, parachute, partner bands). ${ }^{14}$

Sloping surfaces are widely used in training for sprint running. Data on the effects of inclined surfaces (uphill or downhill) on the kinematic and postural characteristics (defined as the relationship and alignment of the various body segments to one another; Larson 1971$)^{28}$ of sprint running are important for understanding the implications of the use of such slopes for sprint training; they can also be used as a baseline for further research. Kunz and Kaufmann ${ }^{15}$ suggested that inclines greater than $1.7^{\circ}$ should be used in training to improve maximum sprint speed on the horizontal (even though they provided no information about the rationale for selecting a threshold slope of $1.7^{\circ}$ ). They did not report in any detail the methods that were used, but the uphill and downhill slopes consisted of asphalt road surfaces and the horizontal surface was an artificial track surface, which could have affected their results. ${ }^{15}$ However, these are the only results in the literature on the effects of sprint running on inclined surfaces.

\section{MATERIALS AND METHODS}

Twenty healthy elite football players (age 24.6 \pm 6.1 years old, height $169.7 \pm 10.9 \mathrm{~cm}$, body weight $65.6 \pm 10.7 \mathrm{~kg}$ ) gave their informed consent to serve as subjects in the study. The procedure, benefits, and potential risks of study were explained to the participants before signing the informed consent form and starting the test. The study was approved by the Institutional Ethics Committee of Faculty of Sports Medicine and Physiotherapy, Guru Nanak Dev University, Amritsar.
The study inclusion criteria included the following: Subjects who agreed with the purpose of this study, subjects who had no existing musculoskeletal problems, such as lower-limb fracture and sprain/strain, subjects who had no recent injury to lower limb, subjects who had no existing neurologic problems, and subjects who had no existing respiratory or cardiovascular system problems during running.

All the subjects were instructed to run with proper footwear on the treadmill (Motorized Treadmill, USA, $220 \mathrm{~V}-50 \mathrm{~Hz}$ ) ramp. The starting position of each subject was set so as to ensure the dominant limb always stepped first on the ramp. The gait was analyzed using Maxrtaq Three-dimensional (3D) Motion Analysis System (InnovisionSystems, Michigan).

The running trials were performed repeatedly three times for each of the three locomotion conditions: Incline running at $4.0 \mathrm{~m} / \mathrm{s}$ and $18 \%$ grade, incline running at $4.0 \mathrm{~m} / \mathrm{s}$ and $9 \%$ grade, and level running at $4.0 \mathrm{~m} / \mathrm{s}$ each for 3 minutes. Prior to testing, a brief period ( 4 minutes) of warm-up was given. Kinematic gait parameters measured included stride length $(\mathrm{m})$, stride frequency $(\mathrm{Hz})$, stance duration (actual time in seconds). The joint angles of the lower extremities (hip, knee, and ankle) at heel contact, impact, toe-off, and maximum angle during swing phase were measured. The selected kinematic parameters were calculated at key events in the gait cycle (foot-strike, toeoff, etc.), and averages for joint kinematics were calculated.

Descriptive statistics were calculated for selected gait and joint kinematic variables. A within subject repeated measures analysis of variance (RM ANOVA) design was used [Statistical Package for the Social Sciences (SPSS) Inc., Chicago, IL, version 17]. All significant differences reported were at $\mathrm{p}<0.01$.

\section{RESULTS}

The results of kinematic level vs treadmill slope running demonstrated significant differences in stride length, stride frequency, and stride duration $(\mathrm{p}<0.01)$ (Table 1$)$. Compared with level running, treadmill slope elicited significant differences in lower-limb joint angles at heelstrike, toe-off, during impact, and swing phase $(\mathrm{p}<0.01)$ (Table 2).

Table 1: Summary of general kinematic gait variables by treadmill grade

\begin{tabular}{|c|c|c|c|c|c|c|}
\hline \multirow[b]{2}{*}{ Variables } & \multicolumn{2}{|c|}{$0 \%$} & \multicolumn{2}{|c|}{$9 \%$} & \multicolumn{2}{|c|}{$18 \%$} \\
\hline & Mean & $S D$ & Mean & $S D$ & Mean & $S D$ \\
\hline Stride length (m) & 1.63 & 0.02 & 1.47 & $0.03^{*}$ & 1.25 & $0.02^{* \dagger}$ \\
\hline Stride frequency $(\mathrm{Hz})$ & 1.38 & 0.02 & 1.49 & $0.01^{*}$ & 1.78 & $0.02^{* \dagger}$ \\
\hline Stride duration (s) & 0.21 & 0.02 & 0.19 & $0.01^{*}$ & 0.18 & $0.01^{* \dagger}$ \\
\hline
\end{tabular}

*Indicates comparison between 0 and $9 \%, 9$ and $18 \%(p<0.01)$;

tindicates comparison between 0 and 18\% $(p<0.001)$ 


\begin{tabular}{|c|c|c|c|c|c|c|c|}
\hline \multirow[b]{2}{*}{ Variables } & \multirow[b]{2}{*}{ Joint } & \multicolumn{2}{|c|}{$0 \%$} & \multicolumn{2}{|c|}{$9 \%$} & \multicolumn{2}{|c|}{$18 \%$} \\
\hline & & Mean & $S D$ & Mean & $S D$ & Mean & $S D$ \\
\hline \multirow[t]{3}{*}{ Angle at heel-strike $\left({ }^{\circ}\right)$} & Hip & 25.61 & 0.48 & 35.64 & $0.49^{*}$ & 54.95 & $0.66^{* \dagger}$ \\
\hline & Knee & 20.85 & 0.45 & 35.85 & $0.45^{*}$ & 59.39 & $0.59^{* \dagger}$ \\
\hline & Ankle & -9.13 & 0.24 & -3.15 & $0.24^{*}$ & 6.61 & $0.27^{* \dagger}$ \\
\hline \multirow[t]{3}{*}{ Angle during impact $\left({ }^{\circ}\right)$} & Hip & 4.52 & 0.30 & 2.51 & $0.28^{*}$ & -11.51 & $0.28^{* \dagger}$ \\
\hline & Knee & 25.35 & 0.33 & 15.35 & $0.33^{*}$ & -4.61 & $0.29^{* \dagger}$ \\
\hline & Ankle & 28.58 & 0.31 & 25.58 & $0.31^{*}$ & 18.44 & $0.32^{* \dagger}$ \\
\hline \multirow[t]{3}{*}{ Angle at toe-off $\left({ }^{\circ}\right)$} & Hip & -4.6 & 0.29 & -2.55 & $0.28^{*}$ & 2.62 & $0.25^{\star \dagger}$ \\
\hline & Knee & 22.62 & 0.26 & 21.77 & $0.24^{*}$ & 21.13 & $0.25^{\star \dagger}$ \\
\hline & Ankle & -20.93 & 0.18 & -21.34 & $0.23^{*}$ & -21.95 & $0.19^{* \dagger}$ \\
\hline \multirow{3}{*}{$\begin{array}{l}\text { Maximum angle }\left({ }^{\circ}\right) \\
\text { during swing phase }\end{array}$} & Hip & 46.58 & 0.44 & 56.58 & $0.44^{*}$ & 80.8 & $0.30^{* \dagger}$ \\
\hline & Knee & 132.1 & 0.33 & 133.1 & $0.33^{*}$ & 136.9 & $0.27^{* \dagger}$ \\
\hline & Ankle & 19.96 & 0.29 & 20.96 & $0.29^{*}$ & 24.75 & $0.31^{* \dagger}$ \\
\hline
\end{tabular}

${ }^{*}$ Indicates comparison between 0 and $9 \%, 9$ and $18 \%(p<0.01) ;{ }^{\dagger}$ indicates comparison between 0 and $18 \%(p<0.001)$

In the post hoc analysis results, significant stride frequency differences $(\mathrm{p}<0.01)$ were found between 0 and $9 \%$, between 9 and $18 \%$, and between 0 and $18 \%$ $(p<0.001)$. Stride length between grades of 0 and $9 \%$ and between 0 and $18 \%$ were found to be significantly different $(p<0.01)$. Significant stride duration differences $(\mathrm{p}<0.01)$ were demonstrated between 0 and $9 \%$, between 9 and $18 \%$, and between 0 and $18 \%(\mathrm{p}<0.001)$.

Significant differences $(\mathrm{p}<0.01)$ were found in the hip, knee, and ankle angles between 0 and $9 \%$, between 9 and $18 \%$, and between 0 and $18 \%(\mathrm{p}<0.001)$ at the heel-strike phase of running. During impact, hip, knee, and ankle angles were found to be significantly different $(p<0.01)$ between 0 and $9 \%$, between 9 and $18 \%$, and between 0 and $18 \%(\mathrm{p}<0.001)$. At the toe-off phase, significant differences $(\mathrm{p}<0.01)$ were found in the hip, knee, and ankle angles between 0 and $9 \%$, between 9 and $18 \%$, and between 0 and $18 \%(p<0.001)$. Significant hip, knee, and ankle angles' differences $(\mathrm{p}<0.01)$ were demonstrated between 0 and $9 \%$, between 9 and $18 \%$, and between 0 and $18 \%(\mathrm{p}<0.001)$.

\section{DISCUSSION}

For running and cutting sports, short burst acceleration is one of the primary discriminators between elite and subelite athletes. Coaches and athletes seek training methods to improve acceleration in order to enhance this important performance variable. While there is evidence that both modes may induce positive neuromuscular adaptations that improve sprint speed, there is currently no consensus as to the most effective method (ground-based resistive or incline treadmill method) to train for improved short burst acceleration. ${ }^{16,17}$ Likewise, it is unclear which variable, stride length or stride frequency, provides the greatest adaptation and improvement during neuromuscular training.
Several authors have contended that treadmill training is not as effective as other speed training methods based on the theory of specificity. Because high-speed incline treadmill training does not have identical kinematics or kinetics to over-ground sprinting, it may be argued that increases in performance on the treadmill may not correlate to performance while sprinting on the ground or during sports activities. ${ }^{18}$ However, in more recent work by Swanson and Caldwell, high-intensity incline treadmill training similar to the training utilized in the current study induced several effects related to increased joint power and muscle activation. ${ }^{13}$ The improved acceleration and stride frequency demonstrated by the incline treadmill training group in the current study support the positive effects of 6 weeks of incline treadmill training on ground-based speed measures.

Our data illustrated that high-speed incline running elicited distinct changes in joint kinematic and gait parameters compared with level running at the same speed. These effects are due in part to the higher stride frequency in the incline condition compared to level running. The results supported our hypotheses that the incline condition would generate kinematic differences accompanied by changes in the gait parameters. 19,20

The level running joint kinematics were consistent with other studies. For example, hip and knee angles at foot-strike were similar to those reported by Milliron and Cavanagh ${ }^{16}$ for running at $4.0 \mathrm{~m} / \mathrm{s}$, whereas ankle angles at foot-strike were typical of those exhibited by mid-foot strikers or during sprinting. Kinematic patterns throughout stance mirrored previous studies of level running: Relatively isometric hip motion, knee flexion, and ankle dorsi-flexion during the impact phase, followed by hip and knee extension and ankle plantar-flexion during push-off. $^{20-22}$

The incline condition resulted in higher stride frequency and a greater proportion of the stride cycle spent 
in stance compared with level running. However, the actual time spent in stance for incline was less than for level surface. Also, stride length was reduced during incline. Another feature of the incline condition was the significantly shorter swing phase duration related to the higher stride frequency. ${ }^{23,24}$ As a result, muscular loading at the hip during swing was significantly higher in incline, with greater hip ROM.

Several kinematic alterations at the hip and knee during swing and large differences in joint kinematics during stance were found between incline and level running, suggesting changes in muscular loading unique to the incline condition. Hip, knee, and ankle extensor ROM during stance were all greater in the incline condition. The results showed greater maximum knee flexion, ankle dorsiflexion, and total hip ROM in incline treadmill running compared to level running. The gait parameters at 9 and $18 \%$ treadmill incline showed significant changes in stride length, stride frequency, stance, and swing phase duration. Step length and stride length decreased as incline angle increased. Kawamura and Sun reported a similar results. $25-27,29,30$

\section{CONCLUSION}

Compared to level treadmill running, incline condition demonstrated significant differences in the kinematic gait parameters as well as lower-limb joint angles at key events in the gait cycle. The results of this study may be used as a medical reference for sprint training on a treadmill for the athletes, especially for treadmills with adjustable gradients. It is important for understanding the implications of the use of such slopes for sprint training; they can also be used as a baseline for further research.

\section{ACKNOWLEDGMENT}

Authors would like to thank their participants. The permission was taken from ethical committee of Guru Nanak Dev University, Amritsar, Punjab, India. Jaspal Singh Sandhu provided the set-up for the study. Amrinder Singh planned the study and submitted the study. Arvind Nigam conducted the study.

\section{REFERENCES}

1. Farley CT, Ferris DP. Biomechanics of walking and running: center of mass movements to muscle action. Exerc Sport Sci Rev 1998;26:253-285.

2. Cometti G, Maffiuletti NA, Pousson M, Chatard JC, Maffulli N. Isokinetic strength and anaerobic power of elite, subelite and amateur French soccer players. Int J Sports Med 2001 Jan;22(1):45-51.

3. Fry AK, Kraemer WJ. Physical performance characteristics of American collegiate football players. J Appl Sport Sci Res 1991 Aug;5(3):126-138.
4. Walker JA, Frappier J, Johnson SC, Swanson SC. Effect of a 6-week incline treadmill training program on Wingate test results and 40-yard sprint times. Med Sci Sports Exerc 2000;32(5):S362.

5. Jacobs R, Bobbert MF, van Ingen Schenau GJ. Function of mono- and biarticular muscles in running. Med Sci Sports Exerc 1993 Oct ;25(10):1163-1173.

6. Klein RM, Potteiger JA, Zebas CJ. Metabolic and biomechanical variables of two incline conditions during distance running. Med Sci Sports Exerc 1997 Dec;29(12): 1625-1630.

7. Buzek F, Cavanagh P. Stance phase knee and ankle kinematics and kinetics during level and downhill running. Med Sci Sports Exerc 1990 Oct;22(5):669-677.

8. Tokuhiro A, Nagashima H, Takechi H. Electromyographic kinesiology of lower extremity muscles during slope walking. Arch Phys Med Rehabil 1985 Sep;66(9):610-613.

9. Messier A, Pittala K. Etiologic factors associated with selected running injuries. Med Sci Sports Exerc 1988 Oct;20(5): 501-505.

10. Jacobs R, van Ingen Schenau GJ. Intermuscular coordination in a sprint push-off. J Biomech 1992 Sep;25(9):953-965.

11. Lichtwark GA, Bougoulias K, Wilson AM. Muscle fascicle and series elastic element length changes along the length of the human gastrocnemius during walking and running. J Biomech 2007;40(1):157-164.

12. Myer GD, Ford KR, Brent JL, Divine JG, Hewett TE. Predictors of sprint start speed: the effects of resistive ground-based vs inclined treadmill training. J Strength Cond Res 2007 Aug;21(3):831-836.

13. Swanson S, Caldwell G. An integrated biomechanical analysis of high speed incline and level treadmill running. Med Sci Sports Exerc 2000 Aug;32(6):1146-1155.

14. Hamill CL, Clarke TE, Frederick EC, Goodyear LJ, Howley ET. Effects of grade running kinematics and impact force. Med Sci Sports Exerc 1984;16:185.

15. Kunz H, Kaufmann D. Biomechanics of hill sprinting. Track Tech 1981;82:2603-2605.

16. Milliron MJ, Cavanagh PR. Sagittal plane kinematics of the lower extremity during distance running. In: Cavanagh PR, editor. Biomechanics of distance running. Champaign (IL): Human Kinetics; 1990. p. 65-100.

17. Nigg BM, Deboer RW, Fisher V. A kinematic comparison of overground and treadmill running. Med Sci Sports Exerc 1995 Jan;27(1):98-105.

18. Elliott BC, Blanksby BA. A cinematographic analysis of overground and treadmill running by males and females. Med Sci Sports 1976 Summer;8(2):84-87.

19. Pink M, Perry J, Houglum PA, Devine DJ. Lower extremity range of motion in the recreational sport runner. Am J Sports Med 1994 Jul-Aug;22(4):541-549.

20. Gottschall JS, Kram R. Ground reaction forces during downhill and uphill running. J Biomech 2005 Mar;38(3):445-452.

21. Cavanagh PR. The biomechanics of lower extremity action in distance running. Foot Ankle 1987 Feb;7(4):197-217.

22. Derrick T, Dereu D, McLean S. Impacts and kinematic adjustments during an exhaustive run. Med Sci Sports Exerc 2002 Jun;34(6):998-1002.

23. Chapman AE, Caldwell GE. Factors determining changes in lower limb energy during swing in treadmill running. J Biomech 1983;16(1):69-77. 
24. Chapman AE, Caldwell GE. Kinetic limitations of maximal sprinting speed. J Biomech 1983;16(1):78-83.

25. Iverson JR, McMahon TA. Running on an incline. J Biomech Eng 1992 Nov;114(4):435-441.

26. Kram R, Griffin TM, Donelan JM, Chang YH. Force treadmill for measuring vertical and horizontal ground reaction forces. J Appl Physiol 1998 Aug;85(2):764-769.

27. Lafortune M, Hennig E. Effects of velocity and uphill slope on tibial shock during running. In: Cotton CE, Lamontagne M, Robertson DGE, Stothart JP, editors. Proceedings of the Fifth Biennial Conference and Human Locomotion Symposium of the Canadian Society for Biomechanics. Canada: University of Ottawa; 1988. p. 94-95.

28. Larson A. 1971. Encyclopedia of Sport Sciences and Medicine, New York: Macmillan.

29. Kawamura K, Tokuhiro A, \& Takechi H. Gait analysis of slope walking: a study of step length, stride width, time factors and deviation in the center of pressure. Acta Medica Okayama 1991; 45(3):179-184.

30. Sun J, Walters M, Svensson N, \& Lloyd D. The influence of surface slope on human gait characteristics: a study of urban pedestrians walking on an inclined surface. Ergonomics 1996; 39(4):677-692. 